\title{
Development of Instruments for Evaluation of Quality of Distance Studies
}

\author{
Lina Tankeleviciene ${ }^{1}$ \\ 1 Siauliai University, Distance Education Study Centre, \\ Visinskio St. 15 a, LT-77156 Siauliai, Lithuania \\ linat@splius.lt
}

\begin{abstract}
The popularity of declaring quality assurance seems to be growing significantly in the last decade, including the field of distance studies and elearning. Unfortunately, the implementation of quality assurance mechanisms on the operational level faces considerable problems. In this article we describe different conceptions of quality of distance studies, the stage of research and implementation of quality assurance in Lithuania, and especially at Siauliai University. We present analysis of two case studies where different methods of the evaluation of distance studies were used: 1) Expert evaluation can prove that distance studies meet posed requirements, and therefore is acceptable in the organization; 2) Students' questionnaires allow to investigate distance studies as a process. Also we present problems that arise while seeking to enhance developed instruments.
\end{abstract}

\section{Introduction}

New possibilities of distance learning also bring new risks and contradictions. For example: 1) Tailoring study programs to the individuals' needs highlights the differences in requirements of different groups of stakeholders; 2) The possibilities to develop study materials of high quality that are better structured and presented in different forms also require more investment in financial and human resources [1]. One of the aims of instructional design specialists in distance studies is to help to decrease the negative impact and to increase the positive impact of factors, mentioned above, among others. In order to achieve this aim, both scientific research and practical case studies in the real context are carried out.

The infrastructure of distance studies and the amount of distance study courses (DSC) have increased rapidly in Lithuania during the last decade [2]. Therefore, the problem of quality of distance studies becomes more topical. Higher education institutions have the biggest experience in the delivery of distance studies in Lithuania. The quality aspect in these studies, which are formal and supported by government, is of high importance. 
The aim of this paper is to analyse mechanisms for assurance of quality of distance studies implemented at Siauliai University and to propose recommendations for its enhancing.

\section{Different Conceptions of the Quality of Distance Studies and its Evaluation Methods}

The 'quality' concept is defined diversely [1, 3], for example: 1) The totality of features and characteristics of a product or service that bear on its ability to satisfy stated or implied needs; 2) Conformance to requirements; 3) Fitness to use. In the terms of quality management, distance studies must be considered as products, services and processes. Different strategies for measurement of different mentioned categories are supposed.

The quality of distance studies is not defined unambiguously in scientific literature. In order to assess, whether the particular case of distance studies is successful, we must know the its main purpose. It can be, for e.g., to decrease training period. The list of indicators for measurement depends on this purpose.

One of the major problems is to define criteria or indicators showing quality of distance studies. Different criteria lists are used, for e.g. 10 axes as in [4]: 1) Content; 2) ODL adaptation and integration; 3) User interface; 4) Use of technologies; 5) Interactivity with the instructional material; 6) Students' support; 7) Communication channel; 8) Acquisition of knowledge; 9) Projects and 'learning by doing'; 10) Assessment and self-assessment. Some of the criteria are not suitable for formal studies, for example: 1) Formal courses must not be 'Open to everybody', because it will bring some confusion over the activities dates, students' support, communication etc. If similar situation occurs, we duplicate courses and adapt one of them for self-learning with no responsibility. 2) 'Understandability of the instructional material' must be acceptable at the University level. Some of the criteria are difficult to achieve with the limits of budget and existing infrastructure. Different users' groups also formulate different needs for quality of distance studies.

Siauliai University was one of the first institutions in Lithuania to begin formalising DS quality assurance using internal documents. The Regulations on the preparation, accreditation and delivery of DSC were approved in the meeting of Commission for Accreditation of DSC at Siauliai University on March 9, 2004. The similar regulations in other institutions are: a) The temporal regulations for accreditation of materials of distance learning modules, prepared at Vilnius Gediminas Technical University; b) The model of quality for DSC material which is used by the Department of Science and Higher Education of the Ministry of Education and Science while organizing competitions for preparation of distance courses; c) The regulation for DSC accreditation, prepared in 2004 by Lithuanian Distance Network project and the Ministry of Education and Science. Janilionis [2] presents contribution towards quality assurance in other Lithuanian organizations.

On the background of the analysis of the mentioned documents, we can draw the conclusion that distance learning course is explored by expert as a static product, not as a process. 


\section{Procedures of Evaluation of DSC at Siauliai University}

Two methods are used for quality evaluation in the domain of distance studies: expert evaluation and evaluation of final users. Here we briefly describe both methods, as they are applied at our University.

The Regulations on the preparation, accreditation and delivery of DSC consist of three parts: a) Requirements; b) Regulations on submitting of DSC for accreditation; c) Regulations on process of evaluation. The following groups of DSC evaluation criteria are used in the accreditation process: a) Information about the course; b) Structure of DSC; c) Content of DSC; d) Students' activities while working alone; e) Organization of evaluation; f) Representation form and design of learning materials. They are listed in the regulations, which are intended for DSC authors, and in the review form, which is intended for evaluators. The criteria are subdivided into separate concrete items, so called sub-criteria. An expert defines, whether the concrete item exists in the DSC. Further he/she draws a conclusion on appropriateness of the concrete criterion. Sub-criteria are used in order to avoid the narrow view on the structure of DSC and to support different teaching strategies.

The members of Commission for Accreditation of DSC are not experts in the subject domain. Therefore, the review from subject domain expert and propositions to delivery DSC from department and faculty must be presented to Commission. The accreditation procedure lets to avoid lecture notes, delivered electronically, treating as DSC. A DSC that was approved by the Commission for Accreditation of DSCs is acknowledged as a methodical aid published by an academic staff.

Despite of all advantages, limitations of the mentioned system can be seen: 1) Used technologies sometimes don't correspond to our present viewpoint on the methodology of distance learning, and confrontation between known best practices and real context arises. 2) The dominant educational aims are often changing. Therefore, documented regulation can come into conflict with new ideas. For example, requirement to assurance of enough quantity of prepared study material leads to demand of transferring information, rather than empowering student to learn. 3) The conclusions of experts are in some aspect subjective: in the ideal model, an evaluator must be an expert in the human-computer interaction domain and in the branch of course knowledge (for example, social sciences).

The conclusions of the experts don't empower us to decide unambiguously about the fitness of DSC, because DSC is not investigated as a process. For that purpose the empirical evaluation is conducted. The results of the study process are influenced not only by well prepared study material and support system, but also by readiness of students, learning competencies, advanced attitudes toward distance learning. Readiness of students and advanced attitudes were investigated by the author in 2001 and 2003 [6]; research has confirmed positive attitudes towards distance learning.

The attitudes of students towards delivered DSC are investigated by the initiative of lecturers at Siauliai University. The results of research are used locally. Usually the assessment of DSC is recorded using Likert scale and the main idea is to identify more important advantages and shortcomings. The following schema for the improvement of DSC was foreseen:

1. Formulation of shortcoming of DSC. 
2. Matching of students' demands and requirements of organization:

- Identifying the importance of characteristics of DSC for final user; identifying intensiveness and frequency of shortcomings.

- Identifying technological tendencies, necessary technologies, educative tendencies, priorities of organization, aims and restrictions of study program or subject module, regulating documents.

3. Improvement of DSC.

This schema was used in surveys, conducted in 2005-2007. The different questionnaires were chosen, gaps in different aspects (course structure, support, etc.) were obtained and improvement directions for each DSC were highlighted.

\section{Evaluation and Conclusion}

Absence of common agreement on some strategies and main criteria for evaluation of quality of DSCs doesn't allow to achieve reliable and widely used results.

The competencies of an academic enable him/her to improve DSC from these aspects: study material for DSCs, methodology, planning of learning activities, solving technological problems. A DSC must be investigated as a heterogeneous object (product, service, and process) in the aspect of total quality management.

Expert evaluation can prove that DSC meets posed requirements, and therefore is acceptable in the organization. In order to gain high quality, formative and improvement-oriented evaluation mechanisms must be used rather than summative and expert based evaluation.

It is recommended for an academic, who seeks to improve DSCs: to obtain thorough students' opinion; strive to constructive critique; to use open questions in questionnaires - then the responses provide with more qualitative information.

\section{References}

1. J. P. Wilson (Editor), Human Resource Development: Learning \& Training for Individuals \& Organizations (Kogan Page, London, 2005).

2. J. Janilionis et al., Analysis of evaluation of quality of distance studies in Lithuanian and foreign institutions of higher education (in Lithuanian). Final report, made during executing project 'Creation of regulations for evaluation of quality of distance studies and its application', 2006.

3. P. Vanagas, Total quality management (Kaunas, Technologija, 2004).

4. A. Karoulis, A. Pombortsis, Heuristic Evaluation of Web-Based ODL Programs, in: Usability Evaluation of Online Learning Programs, edited by C. Shaoui (Information Science Publishing, London, UK, 2003).

5. Regulations on the preparation, accreditation and delivery of distance studies courses. Approved in the meeting of commission for accreditation of distance studies courses at Siauliai University (March 9, 2004); http://distance.su.lt.

6. L. Tankeleviciene, S. Turskiene, Research on attitudes towards distance learning, Pedagogika, No 69, 2003, pp. 223-229. 